\title{
Prevalence and Risk Factors of Gastrointestinal Nematodes Infections in Small Ruminants in Tullo District, Western Harerghe, Ethiopia
}

\author{
Mekuanint Getachew ${ }^{1}$, Reta Tesfaye ${ }^{2 *}$ and Eneyew Sisay ${ }^{3}$ \\ ${ }^{1}$ Oromia National Regional State, West Hararge Zone, Boke District, Veterinary Clinic, Ethiopia \\ ${ }^{2}$ College of Veterinary Medicine and Agriculture, Addis Ababa University, Ethiopia \\ ${ }^{3}$ Amhara National Regional State, South Gondar Administration Zone, Livestock Resources Office, Ethiopia
}

\begin{abstract}
A cross-sectional study was carried out in sheep and goats kept under extensive management system in Tullo district, Western Harerghe zone of Oromia Regional State, Ethiopia, during the period from November, 2013 to April, 2014. The main objectives of the study were to estimate the prevalence of nematode infection in small ruminants and to assess associated risk factors with its occurrence. A total of 384 fecal samples were collected from 168 sheep and 216 goats. The samples were examined using floatation technique and eggs per gram of faeces were determined. The overall prevalence for the nematode infection was 50.8\% (195/384). Different nematode eggs including Strongyle $(177,46.1 \%)$, Strongyloides $(35,9.1 \%)$ and Trichuris eggs $(31,8.1 \%)$ were identified. The mean eggs per gram count showed that, $100(56.5 \%)$ were heavily infected, $61(34.5 \%)$ were moderately infected and the remaining were lightly infected. The coproculture examination from the positive samples for strongyle eggs revealed the presence of Trichostrongylus species (sp), Haemonchus sp., Oesophagostomum sp., Cooperia sp., and Bunostomum sp. Gastrointestinal nematode parasitism is more prevalent $(A O R=2.23)$ in sheep as compared to goats. It was also higher in animals with poor $(A O R=4.54)$ and medium body conditions $(A O R=2.02)$ as compared to animals with good body conditions. However, there was no statistically significant association between the occurrence of the infection and age, sex and origin of the animals'. In conclusion, gastrointestinal nematode parasites were highly prevalent in the study area and this could hamper health and productivity of the small ruminants. Thus, strategic control of nematode parasites should be planned and implemented to reduce the economic losses and welfare problems of the animals.
\end{abstract}

Keywords: Ethiopia; Fecal samples; Goats; Nematodes; Prevalence; Risk factors; Sheep

\section{Introduction}

Ethiopia possesses an estimated population of 25.5 million sheep and 24.06 million goats. Sheep and goats are raised for different purposes in the country. They are kept primarily for breeding purpose. Besides, sheep are kept for wool and mutton while goats are kept for milk and meat [1].

Sheep and goat production depends on feed supplies, good health practices and appropriate animal husbandry management [2,3]. Parasites, especially gastrointestinal nematodes, remain the parasites of most concern to small ruminant breeders. Infection is rampant in most developing countries where poor pastures and the quantities of nutritious food consumed do not cover the nutritional requirements of animals. In addition, there is insufficient veterinary care and the environment is conducive to nematode growth and transmission in these countries [4]. Nematodes have detrimental effects on animal health causing illness and death. They reduce voluntary feed intake and efficiency of feed utilization and are major contributors to reduced meat, milk and wool production [5]. Degree of nematode infection depends mainly upon the age of the host, the breed, the parasite species involved, and the epidemiological patterns which include husbandry practices and physiological status of the animals. More importantly, environmental conditions such as temperature, rainfall and humidity are major factors to the development of nematode eggs and free living stages $[6,7]$.

Many studies have been conducted to estimate the prevalence of nematode parasites in Ethiopia. Accordingly, the results varied greatly among different parts of the country. Even though, there is large population of small ruminants in the study area, the prevalence and risk factors of gastro-intestinal nematode parasite infection has not been reported. The knowledge of the prevalence and risk factors would help in designing strategies to control and prevent nematode infection. Therefore, the main objectives of this study were to determine the prevalence of ovine and caprine gastro-intestinal nematode parasites and assess associated risk factors with its occurrence in Tullo werda. Besides, it was aimed at determining degree of infection for the stongyles.

\section{Materials and Methods}

\section{Description of the study area}

The study was conducted in Tullo destrict, Western Hararghe zone, Oromiya regional state, Eastern Ethiopia. The district is located $370 \mathrm{~km}$ east of Addis Ababa. The mean minimum and maximum temperature in the distric is $18^{\circ} \mathrm{C}$ and $20^{\circ} \mathrm{C}$ respectively. The agro-ecology of the district consists of high land (43.3\%) and mid land (56.7\%). The total area coverage of the district is 45679 hectares, of which 30275 hectares is cultivated land. The estimated animal population in the area is about 117,070 cattle, 12,918 ovine, 37,226 caprine, 5,733 donkeys, 329 horses and 267 mules [8].

*Corresponding author: Reta Tesfaye, Addis Ababa University, College of Veterinary Medicine and Agriculture, Ethiopia, Tel: +251911920797; E-mail: reta.tesfaye@gmail.com

Received January 04, 2017; Accepted February 17, 2017; Published February 20, 2017

Citation: Getachew M, Tesfaye R, Sisay E (2017) Prevalence and Risk Factors of Gastrointestinal Nematodes Infections in Small Ruminants in Tullo District, Western Harerghe, Ethiopia. J Vet Sci Technol 8: 428. doi: 10.4172/2157-7579.1000428

Copyright: @ 2017 Getachew M, et al. This is an open-access article distributed under the terms of the Creative Commons Attribution License, which permits unrestricted use, distribution, and reproduction in any medium, provided the original author and source are credited. 


\section{Study animals}

Randomly selected sheep and goats kept under traditional extensive system were included in this study. All sheep and goats were local breeds. Both sex and all age groups were included.

\section{Study design}

A cross sectional study was conducted from November, 2013 to April, 2014 to determine the prevalence of gastro-intestinal nematode parasites in small ruminants using coproscopic examination. Body condition scoring of sampled animals was carried out according to the method described by Boden [9] and categorized into three scores as poor, medium and good. The age of the animals were estimated by asking the owners and also by looking the dentition pattern of the animals. Small ruminants with all temporary incisor teeth were considered as young while small ruminants with one or more permanent incisor teeth were consider as adults.

\section{Sampling method and sample size determination}

Multi-stage random sampling procedure was used to select the study animals. First Tullo district was selected from Western Hararghe zone. Then out of the 30 peasant associations (PAs) of Tullo district, 5 PAs were randomly selected. Almost equal proportion of small ruminants i.e., 77 from the four PAs and 76 from the remaining one were selected. Simple random sampling technique was used to select individual study animals. The sample size was determined by taking $50 \%$ expected prevalence and 95\% confidence level using the formula described by Thrusfield [10]. Accordingly, a total of 384 sheep and goats were sampled. where; $n=$ required sample size; $d=$ desired absolute precision; $\mathrm{P}_{\exp }=$ expected prevalence.

\section{Fecal sample collection and examination}

A total of 384 fresh faecal samples were collected directly from the rectum of selected animals and the samples were placed in a labeled separate screw capped bottles. During sampling, age, sex, species and body condition were recorded through observation. Finally, the collected samples were kept in cool box until it reached Hirna Regional Veterinary Laboratory for coprological investigation. The majority of samples were processed on the same day of sample collection. Those samples which were not examined immediately after the arrival at laboratory were stored at $+4^{\circ} \mathrm{C}$ and examined the next day early in the morning.

The collected faecal specimens were processed and examined by direct faecal floatation technique for qualitative investigation of the types of gastro-intestinal nematode eggs following the standard procedure indicated by Urquhart et al. [11]. The floatation solution used was $\mathrm{NaCl}$ (sodium chloride). Those samples found positive for gastro-intestinal nematode infection were subjected to egg per gram (EPG) counting and the degree of infection was categorized based on a reference given by Solusby [12]. To differentiate Strongyle species involved, eleven samples were subjected to ova culture and then the infective larvae (L3) were differentiated to species level based on their morphologic characteristics described by Urquhart et al. [11].

\section{Data analysis}

Data collected from individual animals and parasitological examination results were entered into Ms-excel spread sheet. Descriptive statistical tools such as frequency and percentages were used to describe the data. The data were analyzed using bivariate and multivariate logistic regression to assess the association of the potential risk factors with the prevalence of the parasites. Variables found to have a p-value of $<0.2$ in bivariate analysis were entered into multivariable logistic regression model for controlling the possible effect of confounders. Odds ratio was used in assessing strength of association. Apparent prevalence of different nematodes species were calculated as follows:

Prevalence $(\%)=($ Number of positive samples/Total number of samples examined) $\times 100 \%$

\section{Results}

In the current study, the coprological examination revealed an overall prevalence of $50.8 \%$ (195/384) for gastrointestinal nematode infection. From the positive cases, strongyles were identified in 177 (46.1\%) samples, Strongyloides spp. in 35 (9.1\%) and Trichuris spp. in $31(8.1 \%)$ samples.

Species and body conditions were identified as possible risk factors associated with nematode infection with both bivariate and multivariate analysis. Accordingly, sheep were about two times more likely to be positive for nematode infections as compared to goats. Besides, animals with poor and medium body conditions were about five and two times more likely to be positive for nematode infections respectively as compared to animals with good body conditions. Other variables such as sex, age, season and PAs were not statistically significantly associated with the occurrence of nematode infection as indicated in Table 1.

The results of quantitative faecal examination using the modified McMaster technique for GIT nematodes of 177 infected sheep and goats indicated that most of them were heavily infected as depicted in Table 2.

Identification of third stage larvae (L3) from 11 coprocultures indicated the existence of different nematode species among the study animals. These species include Haemonchus, Bunostomum, Cooperia, Oesophagostomum and Trichostrongyles spp. as shown in Table 3.

\section{Discussion}

The current study revealed an overall prevalence of about $51 \%$ nematode infection in small ruminants in the study area. This finding agrees with the reports of other researchers; Regassa et al. [6] and Dagnachew et al. [13] who reported 54.1\% and 47.67\% from Ethiopia, respectively. However, it is relatively lower than 79.09\% [14], 76.3\% [15] $59.89 \%$ [16] and $68.1 \%$ [17] reports from different parts of the country. Comparatively lower prevalence was reported by Raza et al. [18] in Pakistan. The reason for the difference might be due to variation in agro-ecology, which could affect survival and development of infective larval stage of nematode parasites. Variation in the use of anthelmentics and grazing practices might also contributed for the difference in the prevalence.

In this study, infections with strongyles were the dominant one among the small ruminants. Infections with Strongyloides spp and Tricuris were also identified with limited proportions. This is in agreement with several studies conducted so far $[6,17,19-22]$ who reported high proportion of strongyle infection. This might be due to the fact that ruminants have different level of resistance for different species of parasitic infections [11].

The prevalence of nematode infection was about two times in sheep than in goats. This observation is consistent with the findings of earlier works in other parts of the world [23-26] that showed higher GI parasites in sheep than in goats. The higher prevalence of nematode parasites found in sheep than in goats might be due to the fact that sheep have frequent exposure to communal grazing land that has been 
Citation: Getachew M, Tesfaye R, Sisay E (2017) Prevalence and Risk Factors of Gastrointestinal Nematodes Infections in Small Ruminants in Tullo District, Western Harerghe, Ethiopia. J Vet Sci Technol 8: 428. doi: 10.4172/2157-7579.1000428

Page 3 of 4

\begin{tabular}{|c|c|c|c|c|}
\hline Risk factors & No. examined & Infected No. (\%) & Odd ratio & Adjusted odd ratio \\
\hline \multicolumn{5}{|c|}{ Species } \\
\hline Sheep & 168 & $104(61.9)$ & $2.23(1.48-3.37)$ & $2.20(1.43-3.86)$ \\
\hline Goat & 216 & $91(42.1)$ & 1 & \\
\hline \multicolumn{5}{|c|}{ Sex } \\
\hline Male & 196 & $102(52.0)$ & $1.11(0.74-1.65)$ & \\
\hline Female & 188 & $93(49.5)$ & 1 & \\
\hline \multicolumn{5}{|c|}{ Age } \\
\hline Young & 159 & $89(56.0)$ & $1.43(0.95-2.15)$ & \\
\hline Adult & 225 & $106(47.1)$ & 1 & \\
\hline \multicolumn{5}{|c|}{ Body condition } \\
\hline Poor & 78 & $57(73.1)$ & $4.52(2.49-8.2)$ & $4.54(2.45-8.41)$ \\
\hline Medium & 154 & $81(52.6)$ & $1.85(1.17-2.5)$ & $2.02(1.25-3.24)$ \\
\hline Good & 152 & $57(37.5)$ & 1 & \\
\hline \multicolumn{5}{|c|}{ PAs } \\
\hline Midegdu & 77 & $40(51.9 \%)$ & $1.06(0.59-1.92)$ & \\
\hline Chaffe & 77 & $38(49.4 \%)$ & $0.85(0.59-1.93)$ & \\
\hline Terkanfeta & 77 & $37(48.1 \%)$ & $0.84(0.43-1.64)$ & \\
\hline Kirekifis & 77 & $37(48.1 \%)$ & $0.84(0.43-1.64)$ & \\
\hline Rectafura & 76 & $43(56.6 \%)$ & 1 & \\
\hline
\end{tabular}

Table 1: Prevalence of gastrointestinal nematodes in small ruminants by species, sex, age, body conditions and PAs.

\begin{tabular}{|c|c|c|}
\hline Intensity of infection & No. of positive (\%) & EPG \\
\hline Light & $16(9.0)$ & $50-799$ \\
\hline Moderate & $61(34.5)$ & $800-1200$ \\
\hline Heavy & $100(56.5)$ & $>1200$ \\
\hline
\end{tabular}

Table 2: Level of infection based on epg count of examined positive animals for nematode parasites.

\begin{tabular}{|c|c|c|c|}
\hline Species & Sheep & Goat & 2 \\
\hline Haemonchus & 5 & 2 & \\
\hline Bunostomum & 2 & 2 & \\
\hline Cooperia & 3 & 2 & 5 \\
\hline Oesophagostomum & 4 & 3 & \\
\hline Trichostrongyles & 5 & 6 & \\
\hline
\end{tabular}

Table 3: Strongle species identified from coproculture.

contaminated by feaces of infected animals. Goats are browsers in behavior but sheep are grazers from the ground where the GI-parasites egg hatches and reaches the infective stage. This observation, however, disagrees with reports from western Oromia [6] and eastern Ethiopia [20] which showed higher prevalence in goats than in sheep. These authors ascribed their observation to the fact that most of the goats in their study were from lowland and mid altitude areas, which are thought to be suitable for survival of the larval stage of the parasites.

The current study indicated that animals with good body condition had less prevalence of nematode infection. This could be due to a better immunity in animals with good body conditions. It may also signify the importance of the parasites in causing weight loss, a characteristic sign of parasite infections [11,27].

In the present study, age wise observation revealed no statistically significant difference in infection of the parasites. This finding is in agreement with reports from Gambia and Kenya that indicated GIT helminthes affect both ages equally [24,28] and there are instances where younger animals were reported with high rate of parasitic infection [16]. In contrary, other authors have documented that nematode infection is higher in adult and old animals than the younger $[11,13,29]$. However, with this study we ascribed the absence of significant difference in parasites infection between ages of animals. This might be as a result of equal chance of exposure for both age groups to the infective stage of the parasite as all are allowed to graze under extensive management system.
This study further revealed that sex of the animal did not show significant association with the prevalence of nematode infection. The absence of association between sexes is consistent with previous reports [6,29-31]. However, Dagnachew et al. [13] reported a higher prevalence of helminth infection in females and Raza et al. [18] have documented higher prevalence of helminth infection in males.

\section{Conclusion and Recommendations}

The gastrointestinal nematodes of small ruminants are one of the important parasitic diseases that obviously result in reduced productivity of sheep and goats. Therefore, the high prevalence of nematode infection observed in the study area indicates potential contribution to limiting the productivity and compromised well being of the animals. Even though the infection was prevalent in both sheep and goats it was more common in sheep than goats. The infection was found higher in animals with poor body conditions. Therefore, particular attention should be given to sheep and animals with poor body condition in control of the nematode infections.

\section{Acknowledgements}

We acknowledge Hirna Regional Veterinary Laboratory for allowing us to use their facility. Particular thanks go to Dr. Dawit Kassaye and Dr. Tsegaye Neggese and Ato Wendosen for their technical support during our research. 
Citation: Getachew M, Tesfaye R, Sisay E (2017) Prevalence and Risk Factors of Gastrointestinal Nematodes Infections in Small Ruminants in Tullo District, Western Harerghe, Ethiopia. J Vet Sci Technol 8: 428. doi: 10.4172/2157-7579.1000428

\section{References}

1. CSA (2013) Federal democratic republic of Ethiopia, agricultural sample survey. Statistical Bulletin 446: 85-87.

2. Khajuria JK, Katoch R, Yada A, Godara R, Gupta SK, et al. (2013) Seasonal prevalence of gastrointestinal helminths in sheep and goats of middle agroclimatic zone of Jammu province. J Parasit Dis. 37: 21-25.

3. Terefe D, Demissie D, Beyene D, Haile S (2012) A prevalence study of internal parasites infecting Boer goats at Adami Tulu agricultural research center, Ethiopia. Journal of Veterinary Medicine and Animal Health 4: 12-16.

4. Coles GC (2005) Anthelmintic resistance--looking to the future: A UK perspective. Res Vet Sci 78: 99-108.

5. Coop RL, Holmes PH (1996) Nutrition and parasite interaction. Int J Parasito 26: 951-962.

6. Fikru R, Teshale S, Reta D, Kiros Y (2006) Epidemology of Gastro Intestinal Parasites of Ruminants in Western Oromiya Ethiopia. Intern Appl Res Vet Med 4: 51-57.

7. Menkir MS, Uggla A, Waller PJ (2006) Epidemiology and seasonal dynamics of gastrointestinal nematode infections of sheep in a semi-arid region of eastern Ethiopia. Veterinary Parasitology 143: 311-321.

8. TADB (2010) Tullo Agricultural Development Beuro Annual Report, Ethiopia

9. Boden E (1991) Sheep and goat practice. In: Boden E (ed.). Practice Handbook Series, London: Bailliere Tindall, p: 272.

10. Thrusfield M (2007) Veterinary epidemiology. 3rd edn. Published by Blackwell Science Ltd., pp: 178-198.

11. Urquhart GM, Aremour J, Dunchan JL, Dunn AM, Jeninis FW (1996) Veterinary parasitology. 2nd edn. The University of Glasgow, Blackwell Sciences, Scotland, pp: 3-137.

12. Solusby EJL (1986) Helminthes, Arthropods and Protozoa of Domesticated Animals. 7th edn. London, UK; Bailliere, Tindall.

13. Dagnachew S, Amamute A, Temegen W (2011) Epidemiology of gastrointestinal helminthiasis of small ruminants in selected sites of North Gondar zone, Northwest Ethiopia. Ethiop Vet J 15: 57-68.

14. Achenef M (1997) Observation on ovine gastrointestinal nematodiasis and coenurosis in sheep populations of Ethiopian highland, Debre Berhan, North Showa. DVM Thesis, AAU, FVM, Debre Zeit, Ethiopia.

15. Moti W (2008) Prevalence of gastrointestinal nematode of sheep and goats in and around Welinchity, Central Ethiopia. DVM Thesis, HU, FVM, Haramaya, Ethiopia.

16. Zerihun $T$ (2012) Helminthosis of sheep and goats in and around Haramaya Southeastern Ethiopia. J Vet Med Anim Health 4: 48-55.

17. Diriba L, Birhanu A (2013) Prevalence of ovine gastrointestinal nematodes in and around Asella, South Eastern Ethiopia. J Vet Med Anim Health 5: 222-228.
18. Raza MA lqbal Z Jabbar A Yaseen M (2007) Point prevalence of gastrointestinal helminthiasis in ruminants in southern Punjab. Pakistan $J$ Helminthol 81: 323-328.

19. Tesfaye H (1998) Ovine and bovine helminthiasis in Kelela, South Wollo. In: Proceedings of EVA conference, Addis Ababa, Ethiopia, p: 30.

20. Abebe W, Eseyas G (2001) Survey of ovine and Caprine gastrointestinal Helminthosis in eastern part of Ethiopia during the dry season of the year. Revue Med Vet 152: 379-384.

21. Temesgen $T$ (2008) Study on prevalence of ovine gastrointestinal parasite in and around Bedele. DVM Thesis, HU, FVM, Haramaya, Ethiopia.

22. Tigist T (2008) Gastrointestinal parasitosis of small ruminants in and around Debre Zeit. DVM Thesis, Haramaya University, Faculty of Veterinary Medicine, Haramaya, Ethiopia

23. Teklye B (1991) Epidemiology of endoparasites of small ruminants in subsaharan Africa. Proceedings of Fourth National Livestock Improvement Conference. Addis Ababa, Ethiopia, 13-15. November, pp: 7-11.

24. Waruiru RM, Mutune MN, Otieno RO (2005) Gastrointestinal parasite infections of sheep and goats in a semi-arid area of Machakos District, Kenya. Bulletin of Animal Health and Production in Africa 53: 25-34.

25. Yoseph T (2009) Prevalence of Small Ruminant Nematode in and around Nekemte. DVM Thesis, College of Agriculture and Veterinary Medicine, Jimma University, Jimma, Ethiopia.

26. Berry B (2011) Gastrointestinal Helminthosis of Domestic Small Ruminants in and around Yabello District, Borana Zone. DVM Thesis, College of Agriculture and Veterinary Medicine, Jimma University, Jimma, Ethiopia.

27. Radostits OM, Gay CC, Hinchcliff KW, Constable PD (2007) Veterinary Medicine: A textbook of the diseases of cattle, horses, sheep, pigs and goats 10th edn., Saunders Ltd, London, UK.

28. Fritsch T, Kaufmann J, Ptister K (1993) Parasite spectrum and seasona epidemiology of gastrointestinal nematodes of small ruminants in Gambia. Vet Parasitol 49: 271-283.

29. Keyyu JD, Kassuku AA, Kyvsgaard NC, Willingham AL (2003) Gastrointestina nematodes in indigenous zebu cattle under pastoral and nomadic management systems in the lower plain of Southern highlands of Tanzania. Vet Res Commun. 3: 371-380.

30. Ghanem YM, Naser MH, Abdelkader AH, Heybe A (2009) An epidemio coprological. study of protozoan and nematode parasites of ruminants in tropical semi-arid district of Somaliland (North of Somalia). Veterinary Medical Journal. 3rd Science Congress. 10-12 May, pp: 768-787.

31. Negas W, Bogale B, Chanie M (2012) Helminth Parasites in Small Ruminants: Prevalence, Species Composition and Associated Risk Factors in and Around Mekelle Town, Northern Ethiopia. European Journal of Biological Sciences 4 91-95. 